\title{
Does Right Coronary Artery Stenosis Increase Morbi-Mortality in Patients Undergoing Coronary Artery Bypass Graft for Left Main Coronary Artery Disease?
}

\author{
M. Aithoussa, A. Abdou, N. Atmani, M. Bamous, Y. Moutakiallah, F. Nya, A. Seghrouchni, \\ A. Hatim, Y. Elbekkali, A. Boulahya \\ Cardiac Surgery Department, Mohammed V Military Hospital, Mohammed V University, Hay Riad, \\ Rabat, Morocco \\ Email: abdessamadabdou@gmail.com
}

Received 3 June 2015; accepted 27 December 2015; published 30 December 2015

Copyright (C) 2015 by authors and Scientific Research Publishing Inc.

This work is licensed under the Creative Commons Attribution International License (CC BY). http://creativecommons.org/licenses/by/4.0/

(c) (i) Open Access

\begin{abstract}
Background: The association of right coronary artery (RCA) stenosis in patients undergoing myocardial revascularization for left main coronary artery (LMCA) stenosis affects the prognosis. This study aimed to compare immediate results of patients with isolated LMCA stenosis and those with combined RCA stenosis. Patients and methods: We retrospectively evaluated 107 consecutive patients with LMCA disease who underwent coronary artery bypass grafts. The patients were divided into two groups: isolated LMCA stenosis $(n=36)$ and LMCA stenosis + RCA stenosis $(n=71)$. Different variables (preoperative, intra operative and post operative) were compared. Results: Patients with LMCA stenosis + RCA stenosis experienced higher prevalence of diabetes mellitus $(p=$ $0.024)$ and smoker $(p=0.032)$. Also left ventricular EF was reduced $(p=0.004)$. Myocardial revascularization was more complete in patients with LMCA stenosis + RCA stenosis $(p=0.033)$, but in-hospital mortality rate was higher $(12.6 \%$ vs $5.5 \%)$ in isolated LLMCA stenosis, but it did not reach statistical significance $(p=0.32)$. Except low output syndrome (LOS) that was frequent in presence of RCA stenosis $(p=0.026)$, no significant difference was found between groups for other complications. Conclusion: The presence of RCA stenosis in patients undergoing CABG for LMCA disease increases 30 day mortality but without significant impact on overall morbidities.
\end{abstract}

\section{Keywords}

Left Main Coronary Artery (LMCA) Stenosis, Left Main Coronary Artery and Right Coronary Artery Stenosis, Coronary Artery Bypass Graft (CABG), Immediate Results 


\section{Introduction}

Unprotected left main coronary artery (LMCA) stenosis occurs in 5\% of patients undergoing coronary angiography [1]. It has a worse prognosis than other forms of coronary artery disease [2]. Coronary artery bypass graft (CABG) surgery has been the standard of care of treatment and currently recommended [3].

Various precious studies evaluating surgical treatment for this disease have reported an in-hospital mortality rate ranging from $1 \%, 7 \%$ to $7 \%[4][5]$.

In recent years, percutaneous coronary intervention (PCI) for left main coronary artery stenosis upgraded from class III indication in 2006 to class IIa in 2011 thanking to improvements in interventional technologies [6].

Today, the best treatment approach is taken in the heart team, not only on the basis of method of revascularization, but also on the assessment of the cardiovascular risk and co-morbidities of the patient.

The presence of severe significant stenosis or total thrombosis of right coronary artery correlates with worse prognosis in non-treated patients and increases a mortality and morbidity after cardiac surgery.

Left main coronary artery stenosis is rarely presented as an isolated lesion (which concerns $6 \%$ - $8 \%$ of coronary patients), but usually (70\% - 90\%) coexists with multivessel disease [7].

The aim of the present study was to evaluate the impact of significant right coronary artery (RCA) stenosis on the immediate result in patients undergoing coronary artery bypass graft surgery for left main coronary stenosis.

\section{Patients and Methods}

Between January 2000 and December 2012, 586 patients underwent CABG, among them 107 patients who had left main coronary artery stenosis (LMCAS) were included in our study. LMCAS was defined as left coronary artery stenosis $\geq 50 \%$. Those patients were devised into two groups: 36 patients had isolated LMCA stenosis (33, $6 \%$ ), and 71 (66, 4\%) had LMCA stenosis associated with RCA stenosis. Significant LMCA stenosis was defined as a reduction of at least $50 \%$ in the luminal diameter of the LMCA. Also, unprotected LMCA stenosis was defined as an association with significant right coronary artery disease. This retrospective study was approved by the local medical ethic committee. We excluded patients with acute myocardial infarction ( $<2$ weeks), hemodynamic instability, cardiogenic choc, mechanical complication (ventricular septal defect, acute mitral ischemic mitral regurgitation, left ventricular aneurysm), combined procedure (CABG + valve surgery). Finally 107 patients were enrolled in the present study.

Anaesthetic technique was used including premedication with diazepam and hydroxyzine, induction with midazolam and fentanyl. After anesthesia-induction, vecuronium or pancuronium was administered to provide muscles relaxation. Surgical procedure was performed in standard fashion. Mammary arteries conduits were harvested whenever possible completed with Saphen vein. Surgery was delayed 5 days if patient received clopidogrel and 2 days when he presented instable angina pectoris despite anti-ischemic therapy. Other drugs were kept until surgery. CPB was conducted with membrane oxygenator under moderate hypothermia $\left(32^{\circ} \mathrm{C}\right)$. Myocardial protection was made with blood cardioplegia at a dose of $10 \mathrm{ml} / \mathrm{kg}$ repeated with half dose every 20 minutes. Left mammary artery was usually used to bypass the left anterior descending coronary artery (LAD). Other coronary arteries received right mammary artery or Saphen vein graft. Post surgical therapy included low weight molecular heparin, aspirin $250 \mathrm{mg} / 24$ hours. Beta-blockers were started 5 days after surgery. Intra-aortic balloon pump (IABP) was used in the following conditions: haemodynamic instability during induction of anesthesia, difficulties to discharge from CPB, low cardiac output syndrome.

\section{Definitions}

The hospital mortality was defined as all deaths within a 30 day period after the operation. Death was classified as cardiac or non-cardiac. Cardiac death was defined as a death from any cardiac cause (MI, heart failure, arythmia) or sudden unexplained death. Death that could not be classified was considered cardiac. Major adverse cardiovascular events (MACE) included death from any cause, myocardial infarction (MI) and stroke. A perioperative myocardial infarction was defined as a new Q wave on the postoperative ECG or creatine kinase MB level greater than $10 \%$ of normal or greater than 5 times the upper limit of normal or increases level of troponin I. Cerebrovascular accident (CVA) was defined as stroke, transient ischemic attacks, and reversible ischemic neurological deficit. 
The Euroscore (European system for cardiac operative risk evaluation) was used to evaluate the clinical risk of death (Figure 1).

\begin{tabular}{|c|c|}
\hline \multicolumn{2}{|r|}{ Patient-related factors } \\
\hline Age & (per 5 years or part thereof over 60 years) \\
\hline Sex & female \\
\hline $\begin{array}{l}\text { Chronic pulmonary } \\
\text { disease }\end{array}$ & longterm use of bronchodilators or steroids for lung disease \\
\hline $\begin{array}{l}\text { Extracardiac } \\
\text { arteriopathy }\end{array}$ & $\begin{array}{l}\text { any one or more of the following: claudication, carotid occlusion } \\
\text { or }>50 \% \text { stenosis, previous or planned intervention on the abdominal } \\
\text { aorta,limb arteries or carotids }\end{array}$ \\
\hline $\begin{array}{l}\text { Neurological dysfunction } \\
\text { disease }\end{array}$ & severely affecting ambulation or day-to-day functioning \\
\hline Previous cardiac surgery & requiring opening of the pericardium \\
\hline Serum creatinine & $>200 \mathrm{~m} \mathrm{micromol} / \mathrm{L}$ preoperatively \\
\hline Active endocarditis & $\begin{array}{l}\text { patient still under antibiotic treatment for endocarditis at the time of } \\
\text { surgery }\end{array}$ \\
\hline $\begin{array}{l}\text { Critical preoperative } \\
\text { state }\end{array}$ & $\begin{array}{l}\text { any one or more of the following: ventricular tachycardia or fibrillation } \\
\text { or aborted sudden death, preoperative cardiac massage, preoperative } \\
\text { ventilation before arrival in the anaesthetic room,preoperative } \\
\text { inotropic support, intraaortic balloon counterpulsation or preoperative } \\
\text { acute renal failure (anuria or oliguria }<10 \mathrm{ml} / \text { hour) }\end{array}$ \\
\hline
\end{tabular}

LV dysfunction

moderate or LVEF $30 \%-50 \%$

Recent myocardial poor or LVEF $<30$

Other than isolated CABG

Surgery on thoracic aorta for disorder of ascending, arch or descending aorta 


\section{Statistical Analysis}

SPSS Software version 19.0 (SPSS Inc., Chicago, IL, USA) was used for statistical analysis.

Categorical variables, presented as frequencies and percentages, were compared using the chi-square test $\left(x^{2}\right)$ or Fisher's exact test. Continuous variables, expressed as mean \pm SD or median with range, were compared using student's unpaired t-test or the Mann-Whitney U test, as appropriate.

A p value $\leq 0.05$ was considered statistically significant.

\section{Results}

The preoperative characteristics of all enrolled patients are presented in Table 1. One hundred and seven consecutive patients were treated by CABG. The patients were divided into 2 groups: 36 patients had isolated LMCA stenosis (33.6\%), and 71 (66.4\%) had LMCA stenosis associated with RCA stenosis.

Both groups were similar for age, gender and history of previous MI. Compared with isolated LMCA stenosis, patients with associated RCA stenosis experienced higher prevalence of diabetes mellitus $(p=0.024)$ and smoker $(p=0.032)$.Otherwise, no significant differences were found between the two groups in hypertension and hypercholesterolemia. Associated RCA stenosis with LMCA stenosis included significantly more patients with LV function impairment $(51.2 \% \pm 14.2 \%$ vs $59 \% \pm 12.5 \% \mathrm{p}=0.004)$. The two groups did not differ significantly for associated comorbidities. The mean Euroscore in the RCA stenosis $(4.36 \pm 2.8)$ was significantly higher than in the isolated LMCA stenosis $(2.89 \pm 3) \mathrm{p}=0.02$. Table 2 shows operative data. No elective operation $(\leq 48 \mathrm{~h})$ was necessary in 6 patients $(16.6 \%)$ in the isolated LMCA stenosis group and in 18 patients (25.3\%) in the group with combined LMCA stenosis and RCA stenosis, but it did not reach significant difference $(\mathrm{p}=$ 0.3). In-hospital mortality rate was higher in LMCA stenosis + RCA stenosis (12.6\%) than in isolated LMCA stenosis group (5.5\%) but it did not reach significant difference $(\mathrm{p}=0.32)$. LOS was higher in the patients presenting LMCAS + RCA stenosis $(26.7 \%$ vs $8.3 \% \mathrm{p}=0.026)$, but no significant difference of other post operative complications (acute renal failure, infection, stroke, reexploration for bleeding) was observed between groups (RCA stenosis). This explained the frequency use of intra aortic balloon pump IABP $(p=0.009)$ and more

Table 1. Preoperative characteristics.

\begin{tabular}{|c|c|c|c|}
\hline variable & $\begin{array}{c}\text { Isolated LMCS } \\
\quad \mathrm{n}=36\end{array}$ & $\begin{array}{c}\text { ULMCS } \\
\mathrm{n}=71\end{array}$ & $p$ value \\
\hline Age (years) & $58.9 \pm 9.4$ & $60.5 \pm 10$.è & 0.43 \\
\hline Gender/Female & $6(16.6 \%)$ & 7 (9.8\%) & 0.35 \\
\hline Prior MI & $6(16.6 \%)$ & 21 (29.5\%) & 0.53 \\
\hline Prior PCI & $4(11 \%)$ & $1(1.4 \%)$ & 0.043 \\
\hline Diabetes Mellitus & 12 (33.3) & 40 (56.3\%) & 0.024 \\
\hline Smoker & 15 (41.6\%) & 45 (63.4\%) & 0.032 \\
\hline HT & 11 (30.5\%) & 34 (47.9\%) & 0.086 \\
\hline Dyslipidemia & 12 (33.3\%) & 27 (38\%) & 0.63 \\
\hline CCC class III-IV & $18(50 \%)$ & 34 (47.9\%) & 0.83 \\
\hline NYHA III-IV & $5(13.9 \%)$ & 16 (22.5\%) & 0.28 \\
\hline Renal failure & $1(2.7 \%)$ & $1(1.4 \%)$ & 1.00 \\
\hline PVD & $6(16.6 \%)$ & $20(28.1 \%)$ & 0.19 \\
\hline $\mathrm{EF}<\mathbf{4 0 \%}$ & $5(13.9 \%)$ & 17 (23.9\%) & 0.22 \\
\hline CPOD & $6(16.6 \%)$ & $8(11.2 \%)$ & 0.54 \\
\hline Euroscore & $2.89 \pm 3$ & $4.36 \pm 2.8$ & 0.02 \\
\hline Nbre of CVR & $1.6 \pm 0.9$ & $2.3 \pm 1.1$ & 0.001 \\
\hline
\end{tabular}

MI: myocardial infarction, PCI: percutaneous coronary intervention, HT: hypertension, PVD: peripheral vascular disease, EF: ejection fraction, CPOD: chronic pulmonary obstructive disease, CVR: cardiovascular risk. 
Table 2. Perioperative and postoperative results.

\begin{tabular}{cccc}
\hline variable & Isolated LMCS \\
$\mathbf{n}=\mathbf{3 6}$ & $6(16.6 \%)$ & $\begin{array}{c}\text { ULMCS } \\
\mathbf{n}=\mathbf{7 1}\end{array}$ & p value \\
\hline No elective surgery & $106 \pm 32.9$ & $18(25.3 \%)$ & 0.3 \\
CPB time (min) & $63.5 \pm 20.5$ & $129.4 \pm 37.8$ & 0.002 \\
Aortic cross clamp time (min) & $226.6 \pm 43$ & $78.1 \pm 25.5$ & 0.002 \\
Operative time (min) & $8.5(6-18)$ & $261.2 \pm 54.4$ & 0.001 \\
MV time (hours) & $48(46-66)$ & $16(7-18)$ & 0.21 \\
ICU stay (hours) & $13.2 \pm 9.3$ & $48(48-72)$ & 0.06 \\
Postoperative hospital stay (days) & $2.26 \pm 0.9$ & $12.6 \pm 7.1$ & 0.75 \\
Nbre of grafts & $5(13.9 \%)$ & $2.61 \pm 0.7$ & 0.033 \\
Inotropic support & $6(16.6 \%)$ & $23(32.7 \%)$ & 0.04 \\
IABP & $5(13.8 \%)$ & $30(42.2 \%)$ & 0.009 \\
AMI & $3(8.3 \%)$ & $18(25.3 \%)$ & 0.17 \\
LOS & $1(2.7 \%)$ & $19(26.7 \%)$ & 0.026 \\
In-hospital mortality & $1(2.7 \%)$ & $3(4.2 \%)$ & 0.7 \\
Redo operation for bleeding & $2(5.5 \%)$ & $0(0 \%)$ & $8(11.2)$ \\
\hline Infection & $2(5.5 \%)$ & $9(12.6 \%)$ & 0.33 \\
\hline
\end{tabular}

CPB: cardiopulmonary bypass, MV: Mechanical ventilation, ICU: intensive care unit, IABP: intraaortic balloon pulsation, LOS: low out pout syndrome, MOF: multivisceral organ failure, AMI: acute myocardial infarction.

need of inotropic drugs $(p=0.04)$. The mean duration of a CPB and aortic cross clamp were longer in LMCA stenosis + RCA stenosis group $(p=0.002)$ and $(p=0.002)$ respectively. No significant difference was found between the two groups in mechanical ventilation duration and ICU stay.

There was a significant difference in the numbers of grafts between the two groups ( $p=0.033$ ).

\section{Discussion}

The present study showed that associated RCA stenosis disease with LMCA stenosis increases incidence of adverse events and in-hospital mortality without statistical significance. The prevalence of significant LMCA stenosis varies among reported series, depending on selection criteria [8] [9].

This lesion is found in 3\% to 5\% of patients undergoing coronary angiography, and approximately $9 \%$ to $30 \%$ in patients undergoing CABG [10]-[13]. Our results were in accordance with literature prevalence of LMCA stenosis. LMCA stenosis is frequently accompanied by concomitant involvement of one or more of other epicardial vessels and isolated LMCA stenosis constitutes an unusual clinical entity [14] [15]. The spectrum of clinical presentation with LMCA disease may vary from asymptomatic to sudden death [16]. In our cohort, approximately half of patients in the two groups were symptomatic (class III-IV CCS). Numerous studies have shown that stenosis of LMCA is of critical prognostic importance [17], and it is known to be associated with high rate of complications during and after coronary angiography [18] [19]. Early observational studies demonstrated that long-term prognosis of patients treated medically were poor, with 3 years survival rates of 50\% [11] [20]. Most centers, when diagnose LMCA stenosis give priority to these patients for surgery. The median survival for surgically treated patients is 13.3 years versus 6.6 years in medically treated patients [21]-[23]. Miller and associates in their study of 83 patients with LMCA stenosis, found that $3.6 \%$ of the patients died during or shortly after coronary angiography [24]. As serious cardiac events occur frequently in patients with confirmed significant LMCA stenosis who are waiting CABG, guidelines recommend to operate such patients as quick as possible [3]. Although cardiologists and cardiac surgeons commonly perform urgent CABG in most patients with LMCA stenosis, there is no consensus regarding the ideal interval between the angiographic diagnosis and 
surgery. Previous reports from Maziak et al. [25]. Sharareh et al. [26], Salim et al. [27] found that carefully selected patients with significant LMCA stenosis can safely await surgery without undergoing emergency CABG. In recent retrospective study, Sari Ibrahim et al. [28] investigated the effect of waiting time on in-hospital mortality and morbidity among patients with LMCA stenosis and did not found any difference between the patients who were operated within 7 days and more than 7 days. Most investigators have identified the presence of LMCA disease as an independent predictor of operative morbidity and mortality after CABG. But the presence of other factors adds its negative impact to worse outcome. Also, some investigators found that patients who experienced MACE were older, had higher degree of LMCA stenosis, renal failure, unstable angina or myocardial infarction within 2 weeks and had higher degree of right coronary artery stenosis [28] [29]. LMCA disease is classified into two subtypes: protected and unprotected stenosis depending on the existence or not of good collateral circulation from the RCA [7]. Severe LMCA stenosis associated with RCA stenosis or thrombosis is a serious condition of coronary artery disease that is known to cause severe myocardial ischemic complications [30]. According to current guidelines, surgical revascularization with vascular graft is an absolute indication for patients with unprotected LMCA disease and PCI is an alternative when surgery is not manageable [31] [32]. During induction of anesthesia, and during operation before CPB, decrease in the oxygen supply-demand secondary to suddendrop of coronary blood flow which is not compensated by collateral circulation from RCA (because of RCA stenosis) may cause myocardial infarction [33]. Preoperative prophylactic usage of an IABP is still controversial in patients who have stable hemodynamic parameters but are at high risk [34]. There is no consensus on determining with high risk patients will benefit from IABP in CABG [35]. In two recent studies, Micelli [35] and Cakir [36] observed that LMCA stenosis even without RCA stenosis, was an important risk factor for the need for IABP use. During the first years we used systematically IABP before induction anesthesia, but recently we placed it only in patients who were instable.

\section{Study Limitations}

The main limitation of this study is the small cohort of patients and its retrospective design. The small number of MACE limited the statistical power of the study. Additionally, we could not establish the relationship between the presence of RCA stenosis and worse outcome. Finally, we need prospective controlled and randomized trials to clarify the effect of combined RCA disease during coronary surgery for LMCA disease.

\section{References}

[1] Giannoglou, G.D., Antoniadis, A.P., Chatzizisis, Y.S., Damvopoulou, E., Parcharidis, G.E. and Louridas, G.E. (2006) Prevalence of Narrowing $\geq 50 \%$ of the Left Main Coronary Artery among 17,300 Patients Having Coronary Angiography. American Journal of Cardiology, 98, 1202-1205. http://dx.doi.org/10.1016/j.amjcard.2006.05.052

[2] Yusuf, S., Zucker, D., Peduzzi, P., et al. (1994) Effect of Coronary Artery Bypass Graft Surgery on Survival: Overview of 10-Year Results from Randomised Trials by the Coronary Artery Bypass Graft Surgery Trialists Collaboration. The Lancet, 344, 563-570. http://dx.doi.org/10.1016/S0140-6736(94)91963-1

[3] Eagle, K.A., Guyton, R.A., Davidoff, R., Edwards, F.H., Ewy, G.A., Gardner, T.J., Hart, J.C. and Herrmann, H.C. (2004) ACC/AHA 2004 Guideline Update for Coronary Artery Bypass Graft Surgery: Summary Article. Circulation, 110, 1168-1176. http://dx.doi.org/10.1161/01.CIR.0000138790.14877.7D

[4] d’Allonnes, F.R., Corbineau, H., Le Breton, H., Leclercq, C., Leguerrier, A. and Daubert, C. (2002) Isolated Left Main Coronary Artery Stenosis: Long Term Follow up in 106 Patients after Surgery. Heart, 87, 544-548. http://dx.doi.org/10.1136/heart.87.6.544

[5] Lu, J.C., Grayson, A.D. and Pullan, D.M. (2005) On-Pump versus Off-Pump Surgical Revascularization for Left Main Stem Stenosis: Risk Adjusted Outcomes. The Annals of Thoracic Surgery, 80, 136-142. http://dx.doi.org/10.1016/j.athoracsur.2005.02.001

[6] Levine, G.N., Bates, E.R., Blankenship, J.C., et al. (2011) 2011 ACCF/AHA/SCAI Guideline for Percutaneous Coronary Intervention. A Report of the American College of Cardiology Foundation/American Heart Association Task Force on Practice Guidelines and the Society for Cardiovascular Angiography and Interventions. American College of Cardiology Foundation; American Heart Association Task Force on Practice Guidelines; Society for Cardiovascular Angiography and Interventions. Journal of the American College of Cardiology, 58, e44-e122. http://dx.doi.org/10.1016/j.jacc.2011.08.007

[7] Thompson, R. (1986) Isolated Coronary Ostial Stenosis in Women. Journal of the American College of Cardiology, 7, 997-1003. http://dx.doi.org/10.1016/S0735-1097(86)80217-0 
[8] Topaz, O., Warner, M., Lanter, P., Soffer, A., et al. (1991) Isolated Significant Left Main Coronary Artery Stenosis: Angiographic, Hemodynamic, and Clinical Findings in 16 Patients. American Heart Journal, 122, 1308-1314. http://dx.doi.org/10.1016/0002-8703(91)90570-8

[9] Miller, G.A., Honey, M. and el-Sayed, H. (1986) Isolated Coronary Ostial Stenosis. Catheterization and Cardiovascular Diagnosis, 12, 30-34. http://dx.doi.org/10.1002/ccd.1810120108

[10] Smith Jr., S.C., Dove, J.T., Jacobs, A.K., Kennedy, J.W., Kereiakes, D., Kern, M.J., Kuntz, R.E., Popma, J.J., Schaff, H.V., Williams, D.O., Gibbons, R.J., Alpert, J.P., Eagle, K.A., Faxon, D.P., Fuster, V., Gardner, T.J., Gregoratos, G., Russell, R.O. and Smith Jr., S.C. (2001) ACC/AHA Guidelines of Percutaneous Coronary Interventions (Revision of the 1993 PTCA Guidelines)_Executive Summary. A Report of the American College of Cardiology/American Heart Association Task Force on Practice Guidelines (Committee to Revise the 1993 Guidelines for Percutaneous Transluminal Coronary Angioplasty). Journal of the American College of Cardiology, 37, 2215-2239. http://dx.doi.org/10.1016/S0735-1097(01)01344-4

[11] Conley, M.J., Ely, R.L., Kisslo, J., Lee, K.L., McNeer, J.F. and Rosati, R.A. (1978) The Prognostic Spectrum of Left Main Stenosis. Circulation, 57, 947-952. http://dx.doi.org/10.1161/01.CIR.57.5.947

[12] DeMots, H., Rösch, J., McAnulty, J.H. and Rahimtoola, S.H. (1977) Left Main Coronary Artery Disease. Cardiovascular Clinics, 8, 201-211.

[13] El-Menyar, A.A., Al Suwaidi, J. and Holmes Jr., D.R. (2007) Left Main Coronary Artery Stenosis: State-of-the-Art. Current Problems in Cardiology, 32, 103-193. http://dx.doi.org/10.1016/j.cpcardiol.2006.12.002

[14] Black, A., Cortina, R., Bossi, I., et al. (2001) Unprotected Left Main Coronary Artery Stenting: Correlates of Midterm Survival and Impact of Patient Selection. Journal of the American College of Cardiology, 37, 832-838. http://dx.doi.org/10.1016/S0735-1097(00)01176-1

[15] Bulkley, B.H. and Roberts, W.C. (1976) Atherosclerotic Narrowing of the Left Main Coronary Artery. A Necropsy Analysis of 152 Patients with Fatal Coronary Heart Disease and Varying Degrees of Left Main Narrowing. Circulation, 53, 823-828. http://dx.doi.org/10.1161/01.CIR.53.5.823

[16] El Fawal, M.A., Berg, G.A., Wheatley, D.J. and Harland, W.A. (1987) Sudden Coronary Death in Glasgow: The Severity and Distribution of Chronic Coronary Atherosclerotic Stenoses. British Heart Journal, 57, 420-426. http://dx.doi.org/10.1136/hrt.57.5.420

[17] El-Menyar, A.A., Al Suwaidi, J. and Holmes Jr., D.R. (2007) Left Main Coronary Artery Stenosis: State-of-the-Art. Current Problems in Cardiology, 32, 103-193. http://dx.doi.org/10.1016/j.cpcardiol.2006.12.002

[18] Morton, B.C., Higginson, L.A. and Beanlands, D.S. (1993) Death in a Catheterization Laboratory. Canadian Medical Association Journal, 149, 165-169.

[19] Ko, J.K., Nishimura, R.A., Holmes Jr., D.R. and Bailey, K.R. (1991) Predictors of Early Mortality in Patients with Angiographically Documented Left Main Coronary Artery Disease. Catheterization and Cardiovascular Interventions, 24, 84-87. http://dx.doi.org/10.1002/ccd.1810240203

[20] Lim, J.S., Proudfit, W.L. and Sones Jr., F.M. (1975) Left Main Coronary Arterial Obstruction: Long-Term Follow-Up of 141 Nonsurgical Cases. American Journal of Cardiology, 36, 131-135. http://dx.doi.org/10.1016/0002-9149(75)90515-9

[21] Chaitman, B.R., Fisher, L.D., Bourassa, M.G., Davis, K., Rogers, W.J., Maynard, C., Tyras, D.H., Berger, R.L., Judkins, M.P., Ringqvist, I., Mock, M.B. and Killip, T. (1981) Effect of Coronary Bypass Surgery on Survival Patterns in Subsets of Patients with Left Main Coronary Artery Disease. Report of the Collaborative Study in Coronary Artery Surgery (CASS). American Journal of Cardiology, 48, 765-777. http://dx.doi.org/10.1016/0002-9149(81)90156-9

[22] Takaro, T., Peduzzi, P., Detre, K.M., Hultgren, H.N., Murphy, M.L., van der Bel-Kahn, J., Thomsen, J. and Meadows, W.R. (1982) Survival in Subgroups of Patients with Left Main Coronary Artery Disease. Veterans Administration Cooperative Study of Surgery for Coronary Arterial Occlusive Disease. Circulation, 66, 14-22. http://dx.doi.org/10.1161/01.CIR.66.1.14

[23] Caracciolo, E.A., Davis, K.B., Sopko, G., Kaiser, G.C., Corley, S.D., Schaff, H., Taylor, H.A. and Chaitman, B.R. (1995) Comparison of Surgical and Medical Group Survival in Patients with Left Main Coronary Artery Disease. Long-Term CASS Experience. Circulation, 91, 2325-2334. http://dx.doi.org/10.1161/01.CIR.91.9.2325

[24] Miller Jr., D.W., Tobis, F.M., Ivey, T.D. and Rubenstein, S.A. (1981) Risks of Coronary Arteriography and Bypass Surgery in Patients with Left Main Coronary Artery Stenosis. Chest, 79, 387-392. http://dx.doi.org/10.1378/chest.79.4.387

[25] Maziak, D.E., Rao, V., Christakis, G.T., Buth, K.J., Sever, J., Fremes, S.E. and Goldman, B.S. (1996) Can Patients with Left Main Stenosis Wait for Coronary Artery Bypass Grafting? The Annals of Thoracic Surgery, 61, 552-557. http://dx.doi.org/10.1016/0003-4975(95)00835-7

[26] Sharareh, A., Furber, A., Cochou, O., Boulmier, D., Gillard, M., Allal, J. and Geslin, P. (2002) Is It Necessary to 
Operate Quickly in Patients with Significant Left Main Coronary Stenosis? Archives des maladies du coeur et des vaisseaux, 95, 75-80.

[27] Virani, S.S., Mendoza, C.E., Ferreira, A.C. and de Marchena, E. (2006) Left Main Coronary Artery Stenosis: Factors Predicting Cardiac Events in Patients Awaiting Coronary Surgery. Texas Heart Institute Journal, 33, $23-26$.

[28] Sari, I., Acar, Z., Nurkalem, Z., Uslu, N., Davutoglu, V., Ates, M., Ozer, O., Eren, M. and Aksoy, M. (2007) Preoperative Clinical Status but Not Waiting Time Predicts In-Hospital Outcomes of Surgery in Patients with Left Main Coronary Artery Stenosis. Tohoku Journal of Experimental Medicine, 213, 173-180. http://dx.doi.org/10.1620/tjem.213.173

[29] Légaré, J.F., MacLean, A., Buth, K.J. and Sullivan, J.A. (2005) Assessing the Risk of Waiting for Coronary Artery Bypass Graft Surgery among Patients with Stenosis of the Left Main Coronary Artery. Canadian Medical Association Journal, 173, 371-375. http://dx.doi.org/10.1503/cmaj.050053

[30] Falk, E., Nakano, M., Bentzon, J.F., Finn, A.V. and Virmani, R. (2013) Update on Acute Coronary Syndromes: The Pathologists' View. European Heart Journal, 34, 719-728. http://dx.doi.org/10.1093/eurheartj/ehs411

[31] Fox, K., Garcia, M.A., et al. (2006) Guidelines on the Management of Stable Angina Pectoris: Executive Summary: The Task Force on the Management of Stable Angina Pectoris of the European Society of Cardiology. European Heart Journal, 27, 1341-1381. http://dx.doi.org/10.1093/eurheartj/ehl001

[32] Patel, M.R., Dehmer, G.J., Hirshfeld, J.W., et al. (2009) ACCF/SCAI/STS/AATS/AHA/ASNC 2009 Appropriateness Criteria for Coronary Revascularization. Journal of the American College of Cardiology, 53, 530-553. http://dx.doi.org/10.1016/j.jacc.2008.10.005

[33] Cooper Jr., G.N., Singh, A.K., Christian, F.C., Cashman, C., Vargas, L. and Karlson, K.E. (1977) Preoperative IntraAortic Balloon Support in Surgery for Left Main Coronary Stenosis. Annals of Surgery, 185, 242-246. http://dx.doi.org/10.1097/00000658-197702000-00020

[34] Miceli, A., Fiorani, B., Danesi, T.H., Melina, G. and Sinatra, R. (2009) Prophylactic Intra-Aortic Balloon Pump in High-Risk Patients Undergoing Coronary Artery Bypass Grafting: A Propensity Score Analysis. Interactive CardioVasc Thoracic Surgery, 9, 291-294. http://dx.doi.org/10.1510/icvts.2008.196105

[35] Miceli, A., Duggan, S.M., Capoun, R., Romeo, F., Caputo, M. and Angelini, G.D. (2010) A Clinical Score to Predict the Need for Intraaortic Balloon Pump in Patients Undergoing Coronary Artery Bypass Grafting. The Annals of Thoracic Surgery, 90, 522-526. http://dx.doi.org/10.1016/j.athoracsur.2010.04.035

[36] Cakir, H., Uncu, H., Gur, O., Gur, D.O., Yurekli, I. and Ibrahim, O. (2014) Risk Factors for Intraaortic Balloon Pump Use in Coronary Artery Bypass Surgery. Advances in Clinical and Experimental Medicine, 23, 253-257. http://dx.doi.org/10.17219/acem/37070 